\title{
Letter to the Editor Regarding Efficacy and Safety of Diclofenac and Capsaicin Gel in Patients with Acute Back/Neck Pain: A Multicenter Randomized Controlled Study
}

\author{
Ruben Schwartz (D) · Ivan Urits · Omar Viswanath
}

Received: April 25, 2020 / Published online: July 9, 2020

(C) The Author(s) 2020

\section{Key Summary Points}

The most commonly used topical anesthetic that pain physicians prescribe is diclofenac gel, but it may not be that effective.

This is a response article where we agree with the usage of capsaicin gel alongside diclofenac for maximal patient satisfaction.

Topical anesthetics are safer options for patients with numerous comorbidities, which is common in the chronic pain population.
Digital Features To view digital features for this article go to https://doi.org/10.6084/m9.figshare.12505694.

R. Schwartz $(\square)$

Department of Anesthesiology, Mount Sinai Medical Center of Florida, Miami, FL, USA

e-mail: rubenschwartz@yahoo.com

I. Urits

Department of Anesthesia, Critical Care, and Pain Medicine, Harvard Medical School, Beth Israel Deaconess Medical Center, Boston, MA, USA

O. Viswanath

Valley Anesthesiology and Pain Consultants, Envision Physician Services, Phoenix, AZ, USA
Dear Editor,

We read the study by Predel et al. "Efficacy and Safety of Diclofenac + Capsaicin Gel in Patients with Acute Back/Neck Pain: A Multicenter Randomized Controlled Study" with great interest [1]. We agree with the study's emphasis on the importance of topical analgesics. In the treatment of patients with chronic pain, utilizing a truly multimodal analgesic regimen is of the utmost importance, of which topical analgesics represent a vital spoke on the treatment wheel. In addition, these patients oftentimes have numerous comorbidities that limit the amount of oral analgesics physicians can prescribe to alleviate their patients' symptomatology [2]. Or, they have overused antiinflammatory medications to treat their chronic pain to the point that their liver and kidney function has been negatively impacted. Topical

\section{O. Viswanath}

Department of Anesthesiology, University of Arizona College of Medicine-Phoenix, Phoenix, AZ, USA

O. Viswanath

Department of Anesthesiology, Creighton

University School of Medicine, Omaha, NE, USA 
analgesics have been proven to be effective at treating pain, but more importantly are safer than oral analgesics owing to less systemic absorption [3, 4].

With the tremendous reliance on opioid medications throughout the patient population, there has been a push to move to different modalities for treating chronic pain. Topical analgesics offer a safer option that patients of all ages and comorbidities can utilize. Typically, the non-steroidal anti-inflammatory drugs (NSAIDs) like diclofenac are the first-line therapy for many ailments [5]. There has been some controversy within the pain community of the efficacy of diclofenac. Although it has been shown to be a potent anti-inflammatory, its ability to control a patient's pain is questionable.

Capsaicin gel is a proven option for patients suffering from arthritis, chronic pain, gastrointestinal disorders, and cancer. It works mainly through interaction with the transient receptor potential cation channel subfamily $\mathrm{V}$ member 1 (TRPV1) or capsaicin receptor [6]. The article echoes the immense potential capsaicin gel has as a topical anti-inflammatory promoting substantial pain relief.

The addition of diclofenac with capsaicin potentiated the analgesic effect whereas diclofenac alone showed no benefit compared to the placebo group. This study brings positive findings to light that pain physicians should consider utilizing capsaicin gel along with diclofenac gel as a first-line therapy for their patients with chronic pain rather than simply diclofenac alone. This study exemplifies this point and debunks some of the question about how useful diclofenac therapy is alone. In our practice it is commonplace to escalate analgesic therapy quickly after prescribing diclofenac as a result of insufficient pain relief. We now might have some substantial evidence as to why. We would like to thank the study's authors for bringing to light the importance of continued utilization of topical analgesics and potentially improved way of doing so.

\section{ACKNOWLEDGEMENTS}

Funding. No funding or sponsorship was received for this study or publication of this article.

Authorship. All named authors meet the International Committee of Medical Journal Editors (ICMJE) criteria for authorship for this article, take responsibility for the integrity of the work as a whole, and have given their approval for this version to be published.

Authorship Contributions. Ruben Schwartz: interpretation of data, drafting, and revision of article; Ivan Urits: interpretation of data, drafting, and revision of article; Omar Viswanath: interpretation of data, drafting, critical revision of article.

Disclosures. Ruben Schwartz, Ivan Urits, and Omar Viswanath have to nothing to disclose.

Compliance with Ethics Guidelines. This article is based on previously conducted studies and does not contain any studies with human participants or animals performed by any of the authors.

Peer Review. Please note, contrary to the journal's standard single-blind peer review process, as a letter this article underwent review by a member of the journal's Editorial Board.

Data Availability. Data sharing is not applicable to this article as no datasets were generated or analyzed during the current study.

Open Access. This article is licensed under a Creative Commons Attribution-NonCommercial 4.0 International License, which permits any non-commercial use, sharing, adaptation, distribution and reproduction in any medium or format, as long as you give appropriate credit to the original author(s) and the source, provide a link to the Creative Commons licence, and indicate if changes were made. The images or other third party material 
in this article are included in the article's Creative Commons licence, unless indicated otherwise in a credit line to the material. If material is not included in the article's Creative Commons licence and your intended use is not permitted by statutory regulation or exceeds the permitted use, you will need to obtain permission directly from the copyright holder. To view a copy of this licence, visit http:// creativecommons.org/licenses/by-nc/4.0/.

\section{REFERENCES}

1. Predel H, Ebel-Bitoun C, Peil B, et al. Efficacy and safety of diclofenac + capsaicin gel in patients with acute back/neck pain: a multicenter randomized controlled study. Pain Ther. 2020. https://doi.org/ 10.1007/s40122-020-00161-9.

2. Hylands-White N, Duarte RV, Raphael JH. An overview of treatment approaches for chronic pain management. Rheumatol Int. 2017. https://doi.org/ 10.1007/s00296-016-3481-8.

3. Argoff CE. Topical analgesics in the management of acute and chronic pain. Mayo Clin Proc. 2013;88: 195-205.

4. Ngo AL, Urits I, Yilmaz M, et al. Postherpetic neuralgia: current evidence on the topical film-forming spray with bupivacaine hydrochloride and a review of available treatment strategies. Adv Ther. 2020. https://doi.org/10.1007/s12325-020-01335-9.

5. Rodriguez-Merchan EC. Topical therapies for knee osteoarthritis. Postgrad Med. 2018. https://doi.org/ 10.1080/00325481.2018.1505182.

6. Fernandes ES, Cerqueira ARA, Soares AG, Costa SKP. Capsaicin and its role in chronic diseases. In: Gupta $S$, Prasad S, Aggarwal B, editors. Drug discovery from mother nature. Advances in experimental medicine and biology, vol. 929. Cham: Springer; 2016. p. 91-125. https://doi.org/10.1007/978-3-319-41342-6_ 5. 